\title{
Fleurya Aestuans And Tetrahydroxyflavone Effects On Hepatological Enzymes Of Lead Acetate Induced Toxicity
}

\author{
${ }^{1}$ Charles C. Nwafor, ${ }^{1}$ Etolor F. Timiebi-ere, ${ }^{2}$ Solomon M. Uvoh, ${ }^{2}$ Asara A. Azibalua, ${ }^{3}$ Uduak A. Inwang \\ ${ }^{1}$ Department of Human Physiology, Faculty of Basic Medical Sciences, College of Medicine, Madonna University, PMB 48, Elele, \\ Nigeria. \\ ${ }^{2}$ Department of Human Physiology, Faculty of Basic Medical Sciences, College of Health Sciences, University of Port Harcourt, \\ PMB 5323, Port Harcourt, Nigeria. \\ ${ }^{3}$ Department of Human Physiology, Faculty of Basic Medical Sciences, College of Health Sciences, Alex Ekwueme University, \\ Ndufu-Alike, Nigeria.
}

Corresponding author's email: nwaforcharles3@gmail.com

DOI: 10.29322/IJSRP.11.11.2021.p11956

http://dx.doi.org/10.29322/IJSRP.11.11.2021.p11956

\begin{abstract}
The efficacy of hyro-ethanolic leaf extract of Fleurya aestuans on lead acetate-induced hepatotoxicity in 55 Wistar rats was investigated in this study. Animals weighing between 142.0 and 167.6 grams were split into two groups. A total of four groups make up Phase one. Groups 1 served as control group. Fleurya aestuans leaf extract was given at 50, 75, and $200 \mathrm{mg} / \mathrm{kg}$ to Groups 2 , 3, and 4. Seven groups make up phase two. Group A was control. Group B received only LA ( $2.25 \mathrm{mg} / \mathrm{kg})$, Group C, D, and E received LA $(2.25 \mathrm{mg} / \mathrm{kg})$ and FA extracts $(50,75$, and $200 \mathrm{mg} / \mathrm{kg})$, Group F received LA $(2.25 \mathrm{mg} / \mathrm{kg})$ and tetrahydroxyflavone $(100 \mathrm{mg} / \mathrm{kg})$, and Group $\mathrm{G}$ received only tetrahydroxyflavone $(100 \mathrm{mg} / \mathrm{kg})$, respectively. Blood samples were taken into heparinized tubes after 21 days of extract administration to assess liver functions. Histological examination of the liver was performed after it was taken and processed. The lead acetate only group showed a significant $(\mathrm{p}<0.05)$ rise in liver function markers such as AST, ALT, and ALP. The combination of lead acetate with the extract, on the other hand, resulted in a substantial $(\mathrm{p}<0.05)$ decrease in liver enzymes. As a result, the study suggests that the extract be used to treat liver enzyme dysfunctions, thereby validating its usage by traditional medicine practitioners.
\end{abstract}

Key words: Fleurya aestuans, Tetrahydroxyflavone, Hepatological Enzymes, Liver Parameters.

\section{Introduction}

The principal cause of acute and chronic liver disease is drug or chemical-induced liver harm. Hepatotoxicity can also be caused by other chemical agents, such as those employed in labs and some industrial chemicals (e.g., cadmium, lead), as well as herbal medicines. Heavy metal-induced liver injury is responsible for $50 \%$ of the mobilization and increases of liver enzymes such alanine transaminase (ALT), aspartate transaminase (AST), alkaline phosphatase (ALP), and gamma-glutamyl transpeptidase (GGT) in the blood, resulting in liver failure (1). The use of synthetic drugs in the treatment of liver disease has various drawbacks. As a result, it's critical to investigate the therapeutic potential of medicinal plants with hepatoprotective properties (2). Plant sources are commonly employed in traditional medicine to treat a variety of ailments. Many herbal plants have been found to contain phytochemical elements that are responsible for antifungal, antibacterial, antiinflammatory, antioxidant, cytotoxicity, and wound healing effects, among other things (3). Medicinal plants have been shown to help manage liver dysfunctions in studies (4). Plants have been shown in previous research to play a significant role in reducing the harmful effects of heavy metals. Several studies have also revealed that some plants contain a variety of bioactive compounds that have anti-inflammatory properties (5). The tropical nettle weed Fleurya 
aestuans is one of these plants (FA). FA thrives in a cool atmosphere and is most frequent during the rainy season. It grows in tropical areas and is known by a variety of Nigerian names, including fiyafiya and ofuefue (Yoruba), bulsum fage (Hausa), and ile-nkita (Igbo) (6)

Due to its medicinal components, leaves collected from the plant have been used in traditional medicine to treat ulcers, diabetes, and swellings, as recorded by Adetunji et al. (6) According to GC-FID analysis, the leaves of FA extract include tetrahydroxyflavone (THF), according to a recent study from our center by Charles et al. (7). THF is a polyphenolic molecule that is found in large amounts in the human diet. These chemicals' antioxidant and anti-inflammatory properties are well recognized, and many of them have cancer-fighting potential. Flavonoids have been shown to decrease the expression of vascular endothelial growth factor, cancer cell proliferation, and angiogenesis. It has been shown to activate numerous different processes in the regulation of cancer cells, which is particularly intriguing. In comparison to traditional chemotherapeutic medicines, kaempferol not only promotes apoptosis but also affects a wide range of cells (8).

There are no research findings, however, on the effect of HELEFA (hydroethanolic leaf extract of Fleurya aestuans) on toxicities caused by lead acetate ingestion on liver damage.

\section{Materials and methods \\ Preparation of extract}

A plant taxonomist from the University of Port Harcourt's Department of Plant Science and Biotechnology gathered and verified fresh Fleurya aestuans leaves. The plant was given the herbarium number UPH/P/263. Extraneous materials were removed, and the leaves were mechanically pulverized after being dried at room temperature for one week. $450 \mathrm{~g}$ of dry powdered leaves were defatted and extracted in $400 \mathrm{ml}$ of water-ethanol mixture (30:70) for 72 hours in an extraction jar using a sohxlet device. The extract was concentrated using a rotary evaporator to obtain the crude extract. Until it was needed, the extracted yield was maintained at $4^{\circ} \mathrm{C}$ in a home refrigerator.

\section{Phytochemical screening}

Basic chemical investigations were carried out on hydro-ethanolic leaf extract of Fleurya aestuans using standard techniques as described by Sofowora, (9).

\section{Experimental design}

For the investigation, $55 \mathrm{Wistar}$ rats were used. The rats ranged in weight from 142.0 to 167.6 grams. They were purchased from the Madonna University Animal House in Elele, Nigeria. The rats were kept in plastic cages and given commercial rat food to eat. Prior to the start of the trial, they were allowed to feed and drink as they pleased for seven days to adapt. The animals were then divided into two (2) phases based on their subjective isolation.

\section{Phase 1}

For this investigation, 20 rats were employed, divided into four groups of 5 rats each. The rat classifications are as follows:

Group 1: Control group.

Group 2: Low-dose extract $(50 \mathrm{mg} / \mathrm{kg})$ group

Group 3: Medium-dose extract $(75 \mathrm{mg} / \mathrm{kg})$ group

Group 4: High-dose extract $(200 \mathrm{mg} / \mathrm{kg})$ group

For 21 days, the test groups were given single daily doses of hydro-ethanolic leaf extract of Fleurya aestuans orally

\section{Phase 2}


For this investigation, 35 rats were employed, divided into 7 groups of 5 rats each. Falana and Oyeyipo's (10) approach was used to generate ovarian toxicity using $2.25 \mathrm{mg} / \mathrm{kg}$ of lead acetate. The rat classifications are as follows:

Group A: Control group

Group B: Only lead acetate $(2.25 \mathrm{mg} / \mathrm{kg})$ group

Group C: Lead + Low-dose extract $(50 \mathrm{mg} / \mathrm{kg})$ group

Group D: Lead + Medium-dose extract $(75 \mathrm{mg} / \mathrm{kg})$ group

Group E: Lead + High-dose extract $(200 \mathrm{mg} / \mathrm{kg})$ group

Group F: Lead + Tetrahydroxyflavone $(100 \mu \mathrm{g} / \mathrm{kg})$ group

Group G: Only Tetrahydroxyflavone $(100 \mu \mathrm{g} / \mathrm{kg})$ group

Both extract and lead acetate were administered orally for a period of 21 days.

\section{Preparation of Serum}

Blood was obtained from rats at random from each group through ocular puncture into sterile containers, spun, and stored in the fridge. Following that, the rats were sacrificed by cervical dislocation.

\section{Determination of AST/ALT (Reitman and Frankel method)}

AST X - Oxoglutarate + L - aspartate GOT L - glutamate oxalogcetate. AST is measured by monitoring the concentration of oxoloacetate hydrazones formed with 2.4 dinitrophenyl - hydrazine. ALT: x- oxogluterate + L - alanime GPT L- glutamate + pyruvate. ALT is measured by monitoring the concentration of pyruvate hydrazone formed with 2,4 dinitrophynyl-hydrazine.

\section{Determination of ALP (Kochmar, J.F and moss, D>W method) Unit U/L}

Alkaline phosphatase acts upon buffered sodium thymolphthalein monophoshate. The addition of an alkaline reagent stops enzyme activity and simultaneously develops a blue chromogen which is measured photometrically.

\section{Determination of bilirubin (Jendrasik and Grof method) unit:Umoll/L}

Total bilirubin is determined in the presence of caffeine, which releases albumin bound bilirubin by the reaction with diazotized sulphanilic acid.

\section{Determination of total protein (Biuret method) unit g/l}

Cupric ions in an alkaline medium, interact with protein peptide bonds resulting in the formatting of a coloured complex.

\section{Determination of albumin (Bromoeresol Green method) unit g/l}

The measurement of serum albumins bases on us binding to the indicator bromoeresol green, (BCG). Complex absorb at 578nm, the absorbance being directly proportional to the conc. Of albumin in the sample.

\section{Histological Examination}

Following the method described by Bancroft and Gamble (11) for fixation, tissue processing, staining, and photomicrography, samples of liver from all groups of rats were histologically prepared at the end of the experiment.

\section{Statistical Analysis}

The mean and standard error of the mean were used to express the findings. With Statistical Package for Social Science, version 20.0, data were analyzed using a one-way analysis of variance followed by the LSD post-hoc test to find significant differences in all parameters (SPSS, USA). Differences with p0.05 values were regarded as statistically significant. 


\section{Results}

Table 1: Phytochemical screening of extract

\begin{tabular}{cccc}
\hline Phytochemicals Constituents & Aqueous extract & Ethanolic extract & $\begin{array}{c}\text { Hydro-ethanolic } \\
\text { extract }\end{array}$ \\
\hline Alkaloid: & $0.019 \mathrm{~g}$ & $0.023 \mathrm{~g}$ & $0.031 \mathrm{~g}$ \\
\hline Flavonoids: & $0.015 \mathrm{~g}$ & $0.017 \mathrm{~g}$ & $0.028 \mathrm{~g}$ \\
Tannins: & $0.018 \mathrm{~g}$ & $0.017 \mathrm{~g}$ & $0.020 \mathrm{~g}$ \\
\hline Carbohydrates: & $0.017 \mathrm{~g}$ & $0.016 \mathrm{~g}$ & $0.020 \mathrm{~g}$ \\
Cardenolide: & $0.016 \mathrm{~g}$ & $0.019 \mathrm{~g}$ & $0.021 \mathrm{~g}$ \\
\hline
\end{tabular}

KEY: Values are presented as mean $\pm \operatorname{sem} . \mathrm{n}=5 .{ }^{\mathrm{a}}=$ mean values are statistically significant compared to control.

Table 2: Values of some liver enzymes of study animals.

\begin{tabular}{|c|c|c|c|c|c|c|c|}
\hline Group & ASTu/l & ALTu/I & ALPu/l & T.Pg/l & ALBg/l & T.Bumol/l & C.Bumol/l \\
\hline $\begin{array}{c}1 \\
\text { (Control) }\end{array}$ & $45.00 \pm 7.02$ & $39.00 \pm 0.00$ & $62.30 \pm 0.02$ & $76.00 \pm 0.01$ & $43.10 \pm 0.00$ & $12.50 \pm 0.02$ & $8.20 \pm 0.00$ \\
\hline $\begin{array}{c}2 \\
\text { (LDEG) }\end{array}$ & $37.04 \pm 0.00$ & $32.06 \pm 0.00$ & $54.40 \pm 1.00^{\mathrm{a}}$ & $87.50 \pm 0.09^{a}$ & $40.30 \pm 0.01$ & $8.80 \pm 0.00$ & $6.60 \pm 0.07$ \\
\hline $\begin{array}{c}3 \\
\text { (MDEG) }\end{array}$ & $41.00 \pm 5.00$ & $28.00 \pm 0.03^{\mathrm{a}}$ & $56.00 \pm 0.07$ & $83.00 \pm 0.00$ & $45.00 \pm 2.00$ & $14.70 \pm 0.01$ & $4.70 \pm 0.00$ \\
\hline $\begin{array}{c}4 \\
\text { (HDEG) }\end{array}$ & $31.00 \pm 0.00^{\mathrm{a}}$ & $27.04 \pm 0.00^{\mathrm{a}}$ & $42.01 \pm 0.00^{\mathrm{a}}$ & $79.40 \pm 0.03$ & $48.00 \pm 0.05$ & $8.50 \pm 0.02$ & $4.90 \pm 0.02$ \\
\hline
\end{tabular}

KEY: Values are presented as mean $\pm \operatorname{sem} . n=5 .{ }^{a}=$ mean values are statistically significant compared to control.

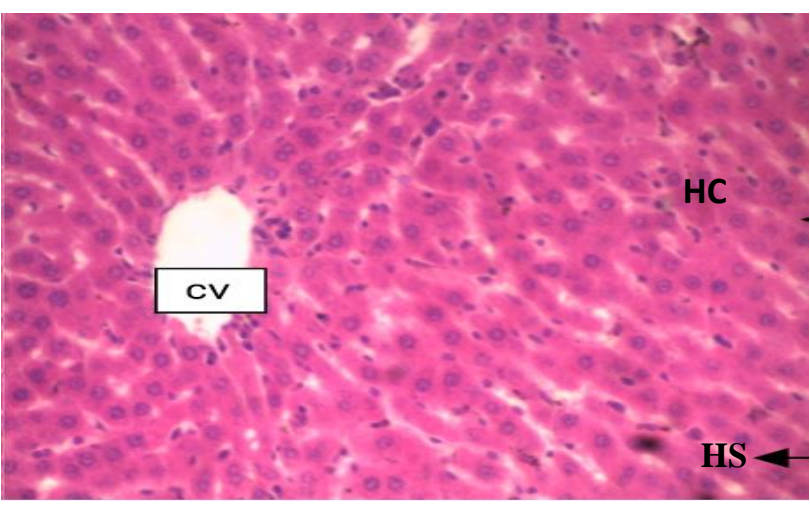

PLT 1 (CONTROL) x 600 Mag

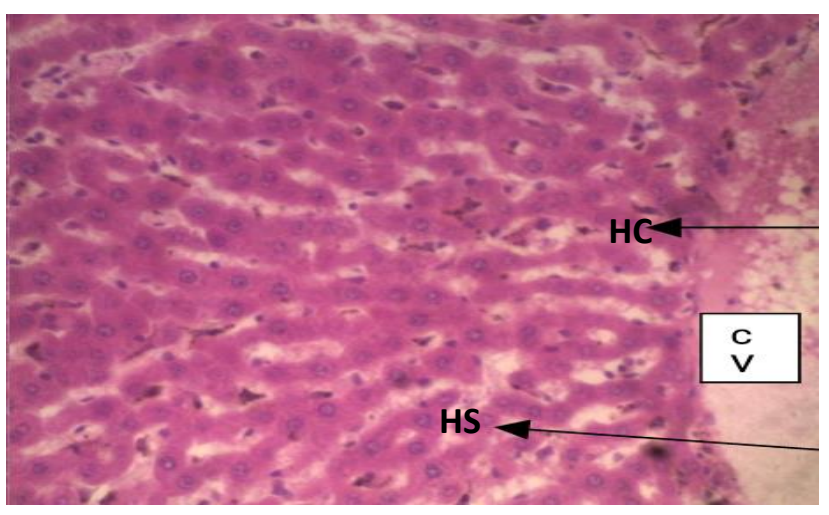

PLT 2 (LDEG) x 600 Mag 


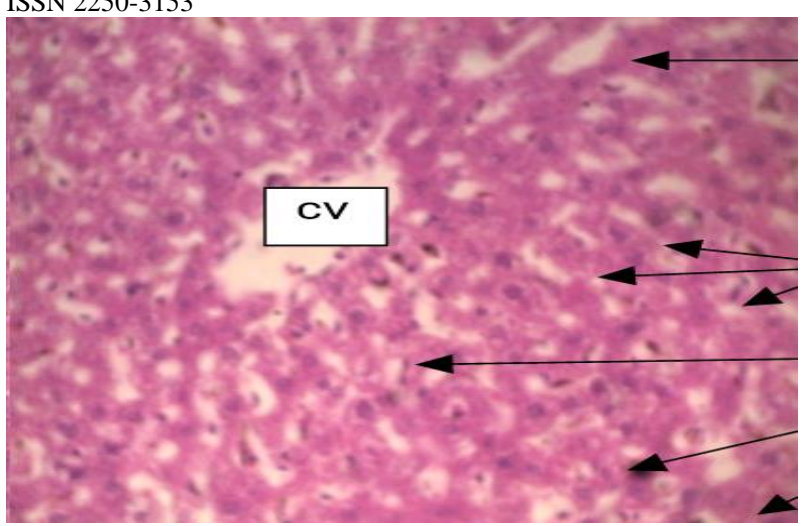

PLT 3 (MDEG) x 600 Mag

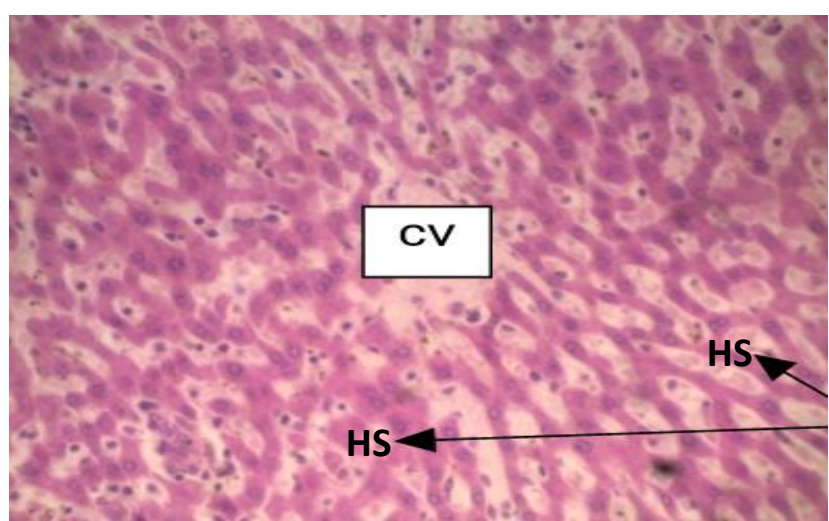

PLT 4 (HDEG) x 600 Mag

Table 3: Values of some liver enzymes following treatment of extract and Kaempferol against lead acetate induced hepatopoisoning.

\begin{tabular}{cccccccc}
\hline Groups & $\mathbf{A S T u} / \mathbf{l}$ & $\mathbf{A L T u} / \mathbf{l}$ & $\mathbf{A L P u} / \mathbf{l}$ & $\mathbf{T . P g} / \mathbf{l}$ & $\mathbf{A L B g} / \mathbf{l}$ & $\mathbf{T} . \mathbf{B u m o l} / \mathbf{I}$ & $\mathbf{C . B u m o l} / \mathbf{I}$ \\
\hline $\mathbf{A}$ & $67.00 \pm 0.03$ & $25.00 \pm 0.00$ & $64.05 \pm 0.02$ & $82.00 \pm 0.00$ & $47.00 \pm 0.01$ & $7.70 \pm 0.00$ & $4.10 \pm 0.06$ \\
$\mathbf{B}$ & $76.05 \pm 0.00$ & $33.00 \pm 0.02$ & $77.00 \pm 0.00$ & $72.00 \pm 0.03$ & $40.00 \pm 0.00$ & $8.20 \pm 0.07$ & $4.50 \pm 0.00$ \\
$\mathbf{C}$ & $58.00 \pm 4.00$ & $24.00 \pm 0.00 \mathrm{~b}$ & $70.00 \pm 0.03$ & $81.00 \pm 0.00 \mathrm{~b}$ & $45.00 \pm 0.05$ & $7.90 \pm 0.00$ & $3.90 \pm 0.04$ \\
$\mathbf{D}$ & $60.00 \pm 0.09$ & $32.05 \pm 0.00$ & $54.00 \pm 0.00 \mathrm{~b}$ & $64.00 \pm 0.03$ & $39.00 \pm 0.00$ & $7.50 \pm 0.05$ & $3.70 \pm 0.00$ \\
$\mathbf{E}$ & $40.50 \pm 0.00^{\mathbf{b}}$ & $26.00 \pm 0.00$ & $50.00 \pm 0.05^{\mathbf{b}}$ & $80.00 \pm 0.00^{\mathbf{b}}$ & $49.00 \pm 0.07^{\mathbf{b}}$ & $7.20 \pm 0.00$ & $4.10 \pm 0.09$ \\
$\mathbf{F}$ & $44.00 \pm 0.01^{\mathbf{b}}$ & $23.00 \pm 0.02^{\mathbf{b}}$ & $35.00 \pm 0.00^{\mathbf{b}}$ & $85.00 \pm 0.04^{\mathbf{b}}$ & $42.00 \pm 0.00$ & $6.50 \pm 0.05$ & $3.20 \pm 0.00^{\mathbf{b}}$ \\
$\mathbf{G}$ & $39.07 \pm 0.00^{\mathbf{b}}$ & $27.00 \pm 0.00$ & $55.00 \pm 0.07^{\mathbf{b}}$ & $83.00 \pm 0.00^{\mathbf{b}}$ & $45.00 \pm 0.03$ & $7.5 .00 \pm 0.00$ & $4.00 \pm 0.07$ \\
\hline
\end{tabular}

KEY:Values are presented as mean \pm sem. $n=5 .{ }^{\mathbf{a}}=$ mean values are statistically significant compared to control. ${ }^{\mathbf{b}}=$ mean values are statistically significant to lead acetate group.

\section{Histological Examination}

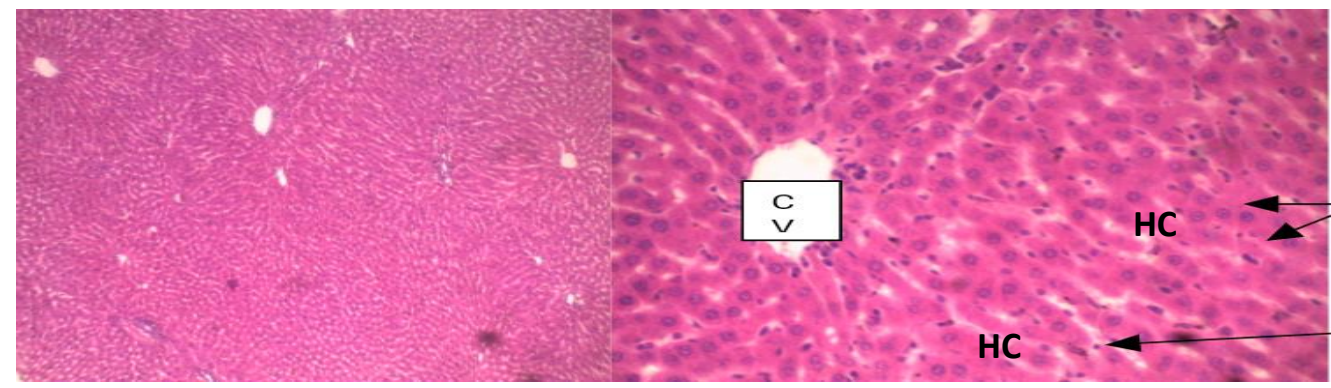

PLT A (CONTROL) X 125 \& X 600 Mag 


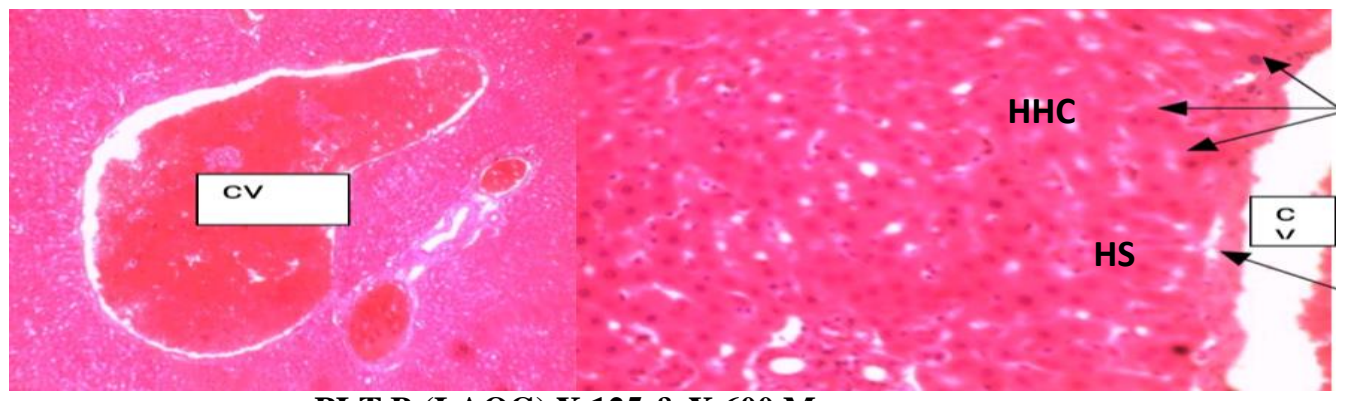

\section{PLT B (LAOG) X $125 \&$ X 600 Mag}

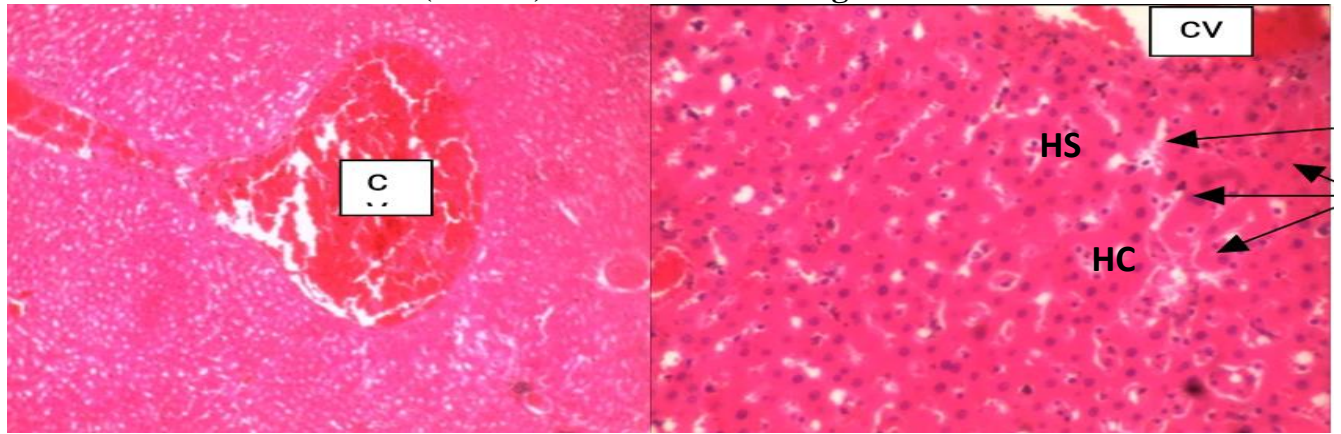

PLT C (LA + LDEG) X $125 \&$ X 600 Mag

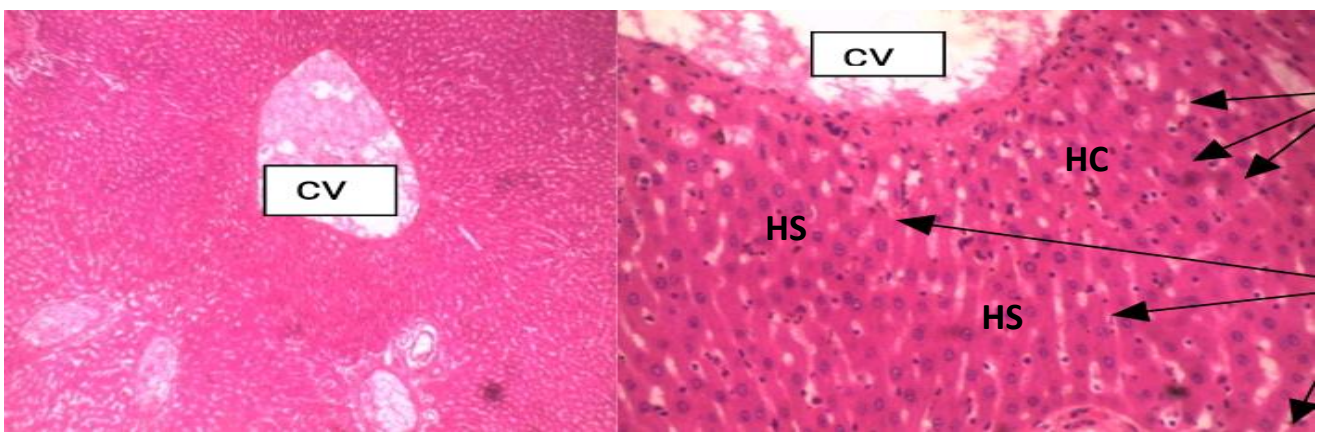

PLT D (LA + MDEG) X $125 \&$ X 600 Mag

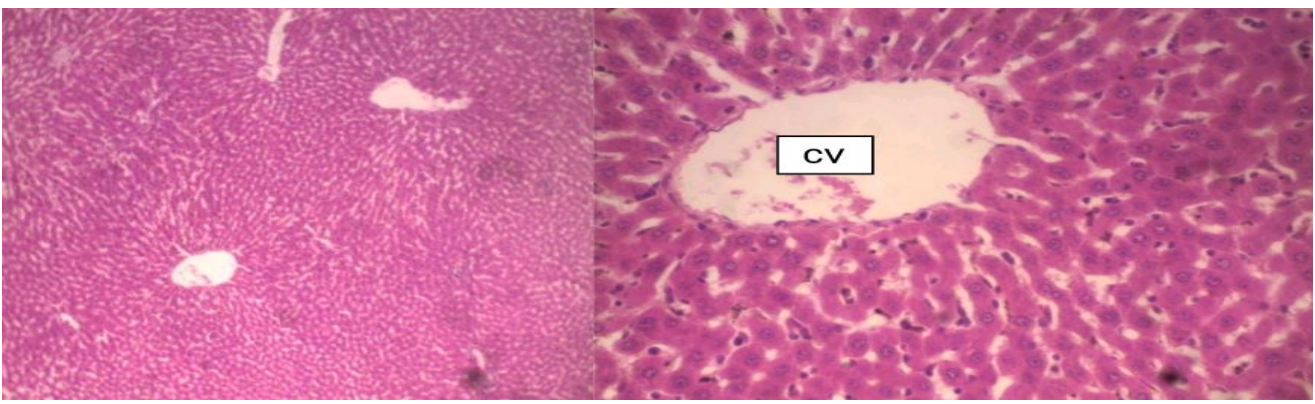

PLT E (LA + HDEG) X $125 \&$ X 600 Mag

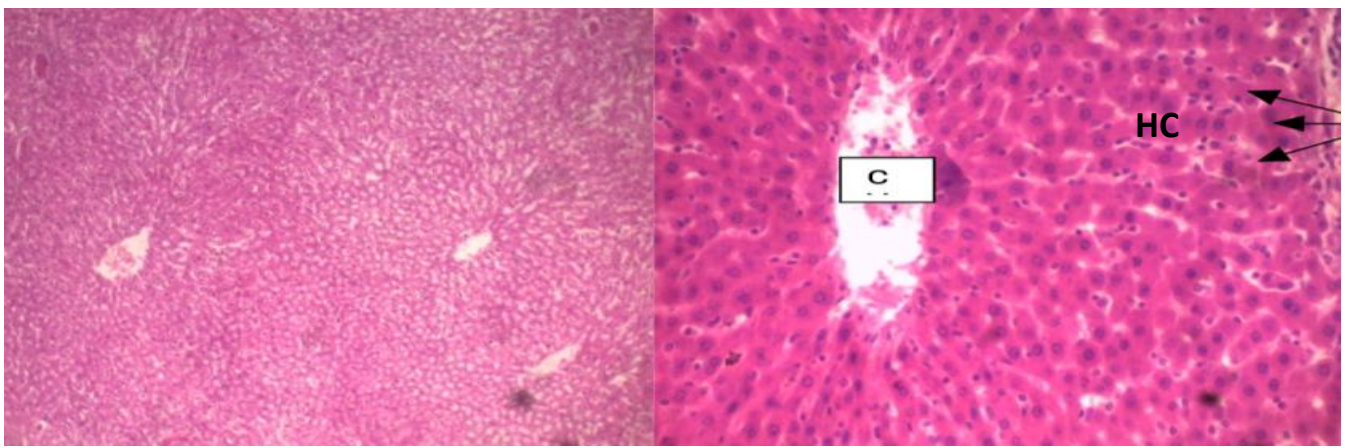

PLTF (LATHE) X $125 \&$ X 600 Mag 


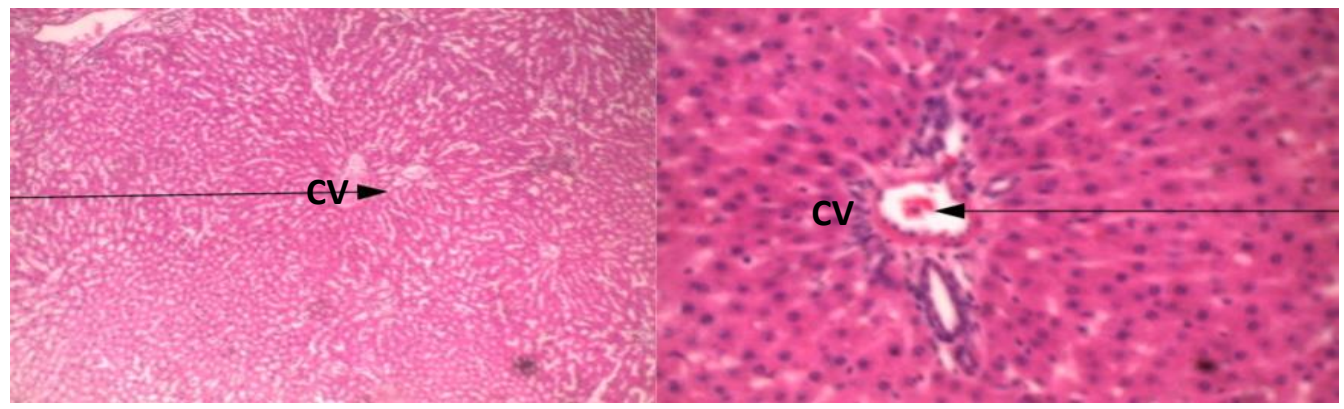

PLT G (THFOG) X 125 \& X 600 Mag

\section{Discussion}

The liver performs a variety of tasks, including insoluble compound biotransformation, plasma protein production, amino acid, carbohydrate, and lipid metabolism, and so on. It is a critical metabolic organ in the body that is known to play a key role in the metabolism of nutrients, medicines, and heavy metals. Human exposure to heavy metals is harmful to one's health, and it continues to be a global public health concern. As a result, heavy metal accumulation in the liver, such as lead acetic acid, causes certain negative consequences on the organ system (12).

The purpose of this study was to see if the hydro-ethanolic leaves of Fleurya aestuans could protect Wistar rats from hepatotoxicity caused by lead acetic acid.

The findings revealed that lead acetic acid treatment resulted in significant elevations in several hepatic enzymes, such as ALP, AST, and ALP, as well as significant decreases in plasma levels of TP, ALB, TB, and CB, respectively. This is in line with previous research that found an increase in liver enzymes following exposure to lead (13).

Elevations of ALT and AST are well-known indicators of liver injury, and the current study backs up previous findings that treatment of lead acetic acid alone causes liver damage in experimental mice. The linkage between the intermediates of the citric acid cycle is well recognized because aminotransferases (ALT and AST) are an essential class of enzymes that link carbohydrate and amino acid metabolism. These enzymes are thought to be indicators of liver damage. Furthermore, because ALP is membrane bound, its alteration is likely to affect membrane permeability and disrupt metabolite transport. Furthermore, increased liver enzymes have been recorded often in $\mathrm{Pb}$-exposed animals, which are utilised as a sign of hepatic tolerance to harmful substances (14).

The fact that $\mathrm{Pb}$ attaches to plasmatic proteins, where it causes changes in a large number of enzymes, could explain the considerable drop in liver enzymes caused by lead acetic acid. It's possible that it influenced protein synthesis and produced reactive oxygen species in hepatocytes. $\mathrm{Pb}$ does not directly cause free radicals to form, but it does have an indirect effect on lipid peroxidation by causing damage to the protective antioxidant barrier. $\mathrm{Pb}$, like cadmium, has a great affinity for amino acid thiol groups, particularly cysteine. $\mathrm{Pb}$ could have harmed the antioxidant barrier by blocking the thiol groups of enzymes like SOD and GST. Dehydratase of delta-aminolevulinic acid is another well-known enzyme that may have been hindered by Pb (ALAD). When ALAD activity is inhibited, aminolevulinic acid (ALA) accumulates, which undergoes auto-oxidation, producing free radicals and causing lipid peroxidation. GSH, which is produced mostly in the liver, is an essential component of the cell defence mechanism. In the second phase of biotransformation, it is engaged in the detoxification of numerous xenobiotics by conjugating hazardous metabolites. SOD's substrate is the superoxide radical anion $(\mathrm{O} 2)$, which is formed when one electron is transferred to molecular oxygen. This causes 
direct damage to biological macromolecules as well as the generation of other reactive oxygen species. SOD plays a vital part in the defence against oxidative stress by keeping the quantity of superoxide radicals low.

Lead acetic acid may have suppressed the levels of GSH and the activities of SOD in the current study. The increased oxidative reaction associated with higher $\mathrm{Pb}$ concentrations in the liver after experimental exposure may be responsible, at least in part, for $\mathrm{Pb}$ induced hepatotoxic injury. The reduced activities of SOD and GST may contribute to the oxidative stress caused by Pb. Flora et al., (15) and Leena et al., (16), all came to similar conclusions.

Nonetheless, the groups treated with extract and tetrahydroxyflavone orally, demonstrated a remarkable reduction in ALP, AST, ALP and significant improvements in TP, ALB, TB, CB, implying that the management of lead poisoning in humans using Fleurya aestuans leaf extract (hydroethanol) and tetrahydroxyflavone (Kaempferol), may be favorable. The amelioration by the extract and tetrahydroxyflavone (kaempferol), might be due to the inhibitory effect on lead acetic acid to bind to plasmatic proteins, perhaps, suppression of ROS production and provocation of protein biosynthesis in the liver.

The hydroethanolic extract of Fleurya aestuans may have reversed the inhibition caused by $\mathrm{Pb}$, implying that the extract had a stimulatory impact on aminolevulinic acid, reducing the production of additional free radicals and lipid peroxidation. Furthermore, oral supplementation of the extract to lead acetate-intoxicated rats may have increased antioxidant potential through influencing antioxidant enzyme activities in addition to lowering liver cell tissue injury, which is consistent with Atef et al (17) findings.

The potency of Fleurya aestuans extract and tetrahydroxyflavone with lead acetic acid on liver histology was also compared in this study.

Plates 1, 4 and A depict a central vein (CV) within a hepatic lobule in a transverse section of rat liver. Hepatocytes or liver cells make up the hepatic lobule. Hepatocytes, like the spokes of a wheel, radiate forth from the central vein. Liver cells produce two-cell thick sheets. The hepatic sinusoids are located between the sheets (HS). The nuclei of the liver cell are darkly pigmented, and the cytoplasm is eosinophilic.

Normal liver architecture, a dilated central vein, larger hepatic sinusoids (HS), hypertrophied hepatocytes (HHC), some vacuolated hepatocytes (VHC), shrinked and weakly stained cell nuclei, and highly stained eosinophilic cytoplasm (HHC) were all seen in Plates 2 and 3.

The liver architecture in plate B (LAOG) was characterized by a dilated central vein crowded with blood, hypertrophied hepatocytes with pyknotic nuclei, ambiguous cell membrane and highly stained eosinophilic cytoplasm, and constricted hepatic sinusoids.

Plate $\mathrm{C}$ shows a dilated central vein that is clogged with blood, normal liver architecture, normal hepatocytes (HC), and normal hepatic sinusoids (HS), all of which are similar to those seen in the control group.

Plates D, E, F, and G, in comparison to the control group, demonstrate a dilated central vein with minimal blood, normal liver architecture, normal hepatocytes, and hepatic sinusoids.

These histological findings clinically imply blood stagnation in the hepatic parenchyma due to poor hepatic venous drainage, which results in hepatomegaly and dilatation of central hepatic veins in group B. (LAOG). Chronic congestion causes hepatocyte atrophy, 
sinusoidal distention, and centrizonal fibrosis, which can proceed to cirrhosis if severe. The extract gradually and gradually repaired this deadly effect on the liver structure.

\section{Conclusion}

This study concludes that intake of Fleurya aestuans, regardless of dose, may be beneficial in reversing liver damage, and so supports its use in botanical medicine and herbalism.

\section{Disclaimer}

The products employed in this study are routinely and often used in our field of study and country. There is no conflict of interest between the writers and makers of the products because we do not plan to use them as a means of pursuing legal action, but rather to further knowledge. Furthermore, the research was not supported by the production firm, but rather by the writers' own efforts.

\section{Consent}

It is not applicable.

\section{Ethical Approval}

Our institution's ethics committee gave its approval to the study.

\section{References}

1. Dixit, Vaibhav A. "A simple model to solve a complex drug toxicityproblem".Toxicology,Research. 2019;8(2):157171.

2. Rajendran A, Sudeshraj R, Sureshkumar S. Potential antidiabetic activity of medicinal plants—a short review. J Phyto Pharm. 2018;7(5):456-459.

3. Zangeneh MM, Bovandi S, Gharehyakheh S, Zangeneh A, Irani P. Green synthesis and chemical characterization of silver nanoparticles obtained using Allium saralicumaqueousnextract and survey of in vitroantioxidant, cytotoxic, antibacterial and antifungal properties. Appl Organometal Chem. 2019;33(7):e461.

4. Abdallah AA, El-Deen NA, Neamat-Allah AN, Abd El-Aziz HI. Evaluation of the hematoprotective and hepato-renal protective effects of Thymus vulgaris aqueous extract on thermally oxidized oil-induced hematotoxicity and hepato-renal toxicity. Comparative Clin Pathol. 2020;29(2):451-461.

5. Bhattacharya S. Medicinal plants and natural products in amelioration of arsenic toxicity: a short review. Pharm Biol. 2017;55(1):349-354.

6. Adetunji Oluwaseyi Adegoke, Jeremiah Olorunjuwon Olugbami, Ayodeji Mathias Adegoke, Michael Adedapo Gbadegesin and Oyeronke Adunni Odunola. Reno-Hepatoprotective and Antidiabetic Properties of Methanol Leaf Extract of Fleurya aestuans in Wistar Rats. Journal of Evidence-Based Integrative Medicine. 2021;26: 1-11

7. Charles CN, Amah-Tariah FS \& Dapper DV. Effect of Hydroethanolic Extract of Fleurya Aestuans on Haematological Parameters and Oxidative Indices of Phenylhydrazin Induced Toxicity. International Journal of Research and Reports in Hematology. 2021;4(3): 17-27,

8. Calderon-Montano, J., Burgos-Moron, E., Perez-Guerrero, C., \& Lopez-Lazaro, M. A review on the dietary flavonoid kaempferol. Mini reviews in medicinal chemistry, 2011;11(4), 298-344.

9. Sofowora, A. (2008). Medicinal plants and traditional medicine in Africa. Ibadan, Nigeria: Spectrum Books Limited 
10. Falana BA, Oyeyipo IP (2012). Selenium and Zinc Attenuate Lead-Induced Reproductive Toxicity in male Sprague-Dawley rats. Research Journal of Medical Science. 6(2):66-70.

11. Bancroft, J.D. and Gamble, M. "Theory and practice of Histological Techniques"; Churchill Livingstone, Edinburgh. 2002; $16-64$.

12. Tajudeen O. Obafemi1*, Amos Onasanya1, Akinwunmi Adeoye2, John A. Falode2, David J. Protective effect of methanolic and flavonoid-rich leaf extracts of Synsepalum dulcificum (Danielli) on lead-acetate-induced toxicity in Wistar albino rats. Journal of Applied Pharmaceutical Science 2019;9(05),065-072.

13. Adikwu E, Deo O, Geoffrey, OBP, Enimeya DA. Lead organ and tissue toxicity: roles of mitigating agents $(\mathrm{Part} 1)$. $\mathrm{Br} \mathrm{J}$ Pharmacol Toxicol, 2013; 4(6):232-40.

14. Omotayo A. Eluwole1,Oluwole I. Adeyemi2 and Moses A. Akanmu. Effects of Launaea taraxacifolia on Lead - Induced Hepatotoxicity in Rats. Journal of Heavy Metal Toxicity and Diseases. 2018;3.2:

15. Flora G, Gupta D, Tiwari A. Toxicity of lead: a review with recent updates. Interdiscip Toxicol. 2012;5: 47-58.

16. Leena K, Veena S, Arti S, Shweta L, Sharma SH. Protective role of coriandrum sativum (coriander) extracts against lead nitrate induced oxidative stress and tissue damage in the liver and kidney in male mice. Int J Appl Biol Pharm; 2011;2(3):6583.

17. Atef M. Attia M, Fatma A, Ibrahim A, Nabil GM, Aziz SW (2019). Antioxidant effects of ginger (Zingiber officinale Roscoe) against lead acetate-induced hepatotoxicity in rats. African Journal of Pharmacy and Pharmacology; 7(20):1213-9. 